\title{
Tomography and thermal state of the Cocos plate subduction beneath Mexico City
}

\author{
Allen Husker ${ }^{1}$ and Paul M. Davis ${ }^{1}$ \\ Received 27 August 2008; revised 24 December 2008; accepted 18 February 2009; published 28 April 2009. \\ [1] The geometry and thermal state of the subducting Cocos plate beneath Mexico City \\ has been enigmatic because of the absence of a deep Wadati-Benioff zone. We present a \\ tomographic image of the slab based on inversion of 8869 teleseismic P wave travel \\ times measured on a portable broadband seismic network. The images combined with \\ receiver function analysis show that the slab runs flat from the coast to near Mexico City, \\ where it dives into the mantle just before the Trans-Mexican Volcanic Belt with a dip of \\ $\sim 75^{\circ}$. It continues down to a depth of $\sim 500 \mathrm{~km}$ at a distance of $400 \mathrm{~km}$ from the \\ trench, where the tomography reveals that the dipping portion ends. As well as standard \\ block tomography, we invert the travel time residuals for the parameters of a thermal \\ slab model and find a slab thickness of $40 \mathrm{~km}$ that is consistent with the (15 Ma) age of the \\ Cocos plate. The combination of a young hot plate and truncation at depth can explain the \\ lack of deep seismicity due to high temperatures and lower negative buoyancy \\ compared with an older, thicker, nontruncated plate.
}

Citation: Husker, A., and P. M. Davis (2009), Tomography and thermal state of the Cocos plate subduction beneath Mexico City, J. Geophys. Res., 114, B04306, doi:10.1029/2008JB006039.

\section{Introduction}

[2] Despite numerous studies, the location and shape of the subducting Cocos plate beneath the Trans-Mexican Volcanic Belt (TMVB) has remained controversial. The Cocos plate was well mapped by seismicity [Pardo and Suarez, 1995] from the trench north to the TMVB where it subducts nearly horizontally (Figure 1). However, the seismicity stops just south of the TMVB. North of the TMVB there are two primary competing theories of the Cocos plate: (1) that it broke away from the ancient Farallon plate along the northern edge of the TMVB [Ferrari, 2004] and (2) that it is continuous [Gorbatov and Fukao, 2005] but aseismic.

[3] The tomograms, as will be seen, show detailed images of the slab. However, because of the limitations of the ray geometry they include unresolved features and artifacts that all tomographic images exhibit. Edge effects were pervasive, and forward modeling revealed that areas that should have velocities of the background model had some small perturbations. In addition, the resolution and errors depend on the overall image dimensions. In order to try to alleviate these problems we followed Deal et al.'s [1999] technique of assuming a slab temperature model to invert for slab properties. However, in contrast to their approach, we solved for model parameters directly from the travel time data using the slab temperature model. Deal et al. [1999] solved for model parameters from the tomographic image.

\footnotetext{
${ }^{1}$ Department of Earth and Space Sciences, University of California, Los Angeles, California, USA.

Copyright 2009 by the American Geophysical Union. 0148-0227/09/2008JB006039\$09.00
}

We used the same thermal model [Davies and Stevenson, 1992] as Deal et al. [1999], derived from the diffusion equation, but we found an error in the slab temperature model, and we derive the correct solution in this paper.

[4] Data were acquired from the Middle American Subduction Experiment (MASE, http://www.tectonics.caltech. edu/mase/). MASE was a collaboration between the University of California, Los Angeles (UCLA) Center for Embedded Networked Sensing (CENS), the Universidad Nacional Autónoma de México (UNAM), and the California Institute of Technology (CIT). The first phase was installed from January 2005 to May 2007. It was composed of seismic stations every 5-6 km running along a line from Acapulco through Mexico City to nearly the Gulf Coast (Figure 1). There were 100 seismic stations in total that ran $550 \mathrm{~km}$. Each seismic station had a Guralp 3T low-noise, broadband seismometer recording at 100 samples per second.

[5] The combined model of the geometry and geodynamics of the Cocos slab using MASE data was given by Pérez-Campos et al. [2008]. We explain in detail the tomography of Pérez-Campos et al. [2008] as well as a thermal model not included in their work.

\section{P Wave Tomography}

[6] To develop the tomographic image, 8869 teleseismic $\mathrm{P}$ wave seismograms were used. The vertical component seismograms were band-pass filtered from 1 to $50 \mathrm{~s}$ to remove high-frequency noise and long-period fluctuations. The theoretical arrival times, obtained from the iasp91 travel time model [Kennett and Engdahl, 1991], were used to phase shift the waveforms so that they lined up on a seismic section. The waveforms were then averaged and individual 


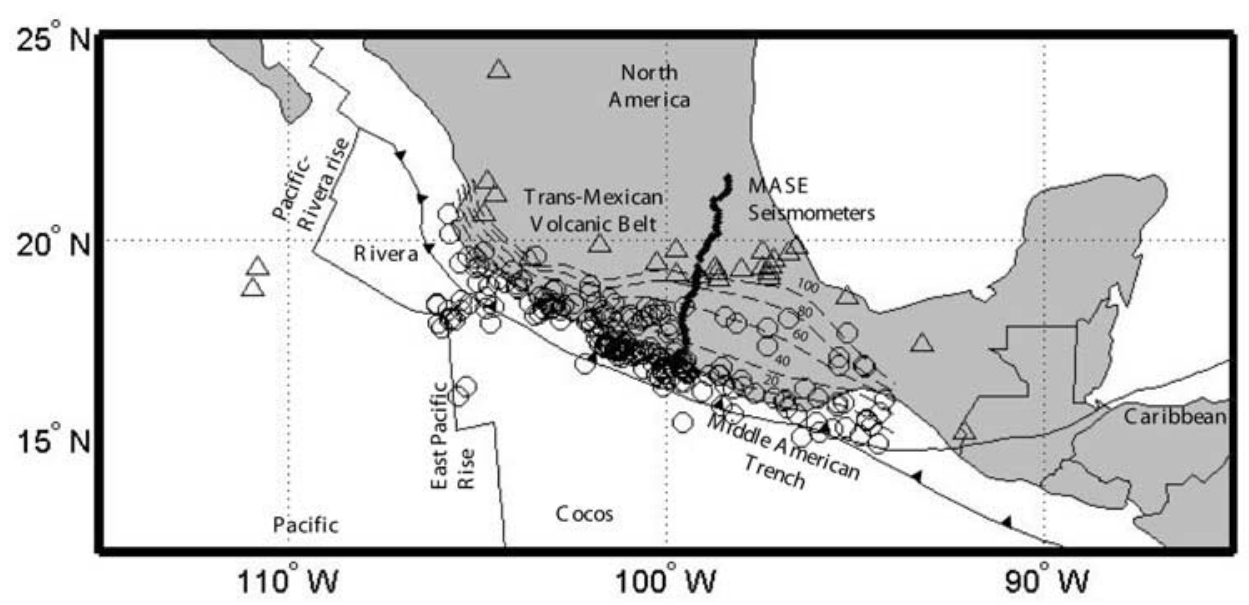

Figure 1. Tectonic setting of Mexico. The triangles are Holocene volcanoes listed by Simkin and Siebert [2002-2007] (see http://www.volcano.si.edu/faq/). The dots running north to south through the middle of the Trans-Mexican Volcanic Belt are the locations of the MASE seismometers. The depth contours of the subducted Cocos plate and the relocated seismicity depicted as circles come from Pardo and Suarez [1995]. The Caribbean-North America plate boundary is not well defined across the North American continent.

waveforms cross-correlated with the average waveform. The difference in the position of the peak of the cross correlation was taken as the difference in the arrival time, $\Delta \mathrm{T} . \Delta \mathrm{T}$ was used as input for the tomography. The mean of the travel time from each earthquake was also removed in order to avoid regional offsets in velocity from the iasp91 model and hypocentral error.

[7] The damped least squares method was used for the inversion. The model space was a two-dimensional (2-D) $20 \mathrm{~km} \times 20 \mathrm{~km}$ grid of points, but as we show below the data have a more coarse resolution of about $80 \mathrm{~km}$. Therefore the resulting $20 \mathrm{~km} \times 20 \mathrm{~km}$ images were smoothed with a 2-D Gaussian filter $(\sigma=16 \mathrm{~km})$. The depth points ranged from 50 to $670 \mathrm{~km}$. $50 \mathrm{~km}$ was chosen as the shallowest depth to leave space to account for the crust for which we used models developed by MASE colleagues as discussed below. The teleseismic rays for $\mathrm{P}$ waves are near vertical above $50 \mathrm{~km}$ and so they cannot resolve crustal velocities. A number of inversions were performed using different model depths. In each case the shape and location of the slab remained the same. The horizontal line of points ranged every $20 \mathrm{~km}$ following the strike of the array, $16.7^{\circ}$ clockwise from north. They started at $-10 \mathrm{~km}$ from the first station in Acapulco and ended at $550 \mathrm{~km}$ which was about $10 \mathrm{~km}$ beyond the last station. The $20 \mathrm{~km} \times 20 \mathrm{~km}$ grid spacing was chosen in order to have about 3 seismic stations for every grid point, i.e., slightly above the spatial Nyquist frequency. The stations ranged from $0 \mathrm{~km}$ to $541 \mathrm{~km}$ inland. The model is composed of 928 grid points in all. In order to determine station and grid spacing in kilometers instead of degrees, stations were mapped to a flat surface using a Mercator projection. The $0^{\circ}$ latitude point of the projection was centered at the 50th station inland to minimize spatial distortion.

[8] Rays were traced through the iasp91 velocity model [Kennett and Engdahl, 1991] to each station. We tested the effect of ray tracing with the addition of the velocity perturbations derived from the inversion, but it made little difference to the results as the perturbations are only on the order of a few percent of the total background. Ray tracing was done through the grid at steps of $2 \mathrm{~km}$ vertical distance. The horizontal distance and position were determined by Snell's law. All steps $\pm 10 \mathrm{~km}$ near a particular grid point were added together to develop the length for the ray at that grid point. Thus, a grid point at $50 \mathrm{~km}$ depth included rays from 40 to $60 \mathrm{~km}$.

[9] In order to strip off effects related to the crust before doing the tomographic inversion we created a combined crustal model including the 2-D P wave velocity model from a previous refraction survey [Valdes et al., 1986] and a 2-D surface $\mathrm{S}$ wave velocity model (A. Iglesias et al., unpublished data, 2007) converted to $\mathrm{P}$ wave velocities assuming a constant $\mathrm{P}$ to $\mathrm{S}$ velocity ratio of $\sqrt{3}$. This assumes a Poisson solid (i.e., the Lamé constants are equal, $\lambda=\mu$ ) as is roughly the case for many Earth materials [e.g., Lay and Wallace, 1995]. The refraction survey [Valdes et al., 1986] was located approximately $180 \mathrm{~km}$ to the east of the MASE line in Oaxaca. The subduction zone was well measured, but inland owing to sparsity of stations, they obtained a simple 1-D layered model. The surface wave model was made with MASE data and is much more detailed inland, but has no details off the coast. Therefore, we superimposed the subducting slab from Valdes et al. [1986] onto the surface wave model (Figure 2). Linear interpolation of the surface wave velocities (A. Iglesias et al., unpublished data, 2007) was used to determine the velocities between the stations and the values for the velocities at the end stations for locations further north and south. We used a Gaussian filter $(\sigma=4 \mathrm{~km})$ to smooth the surface wave velocities before adding the Valdes et al. [1986] slab.

[10] Figure 3 is the $\mathrm{P}$ wave velocity tomogram that results when effects of the crust have been stripped out including topography. The topography was accounted for by assuming 


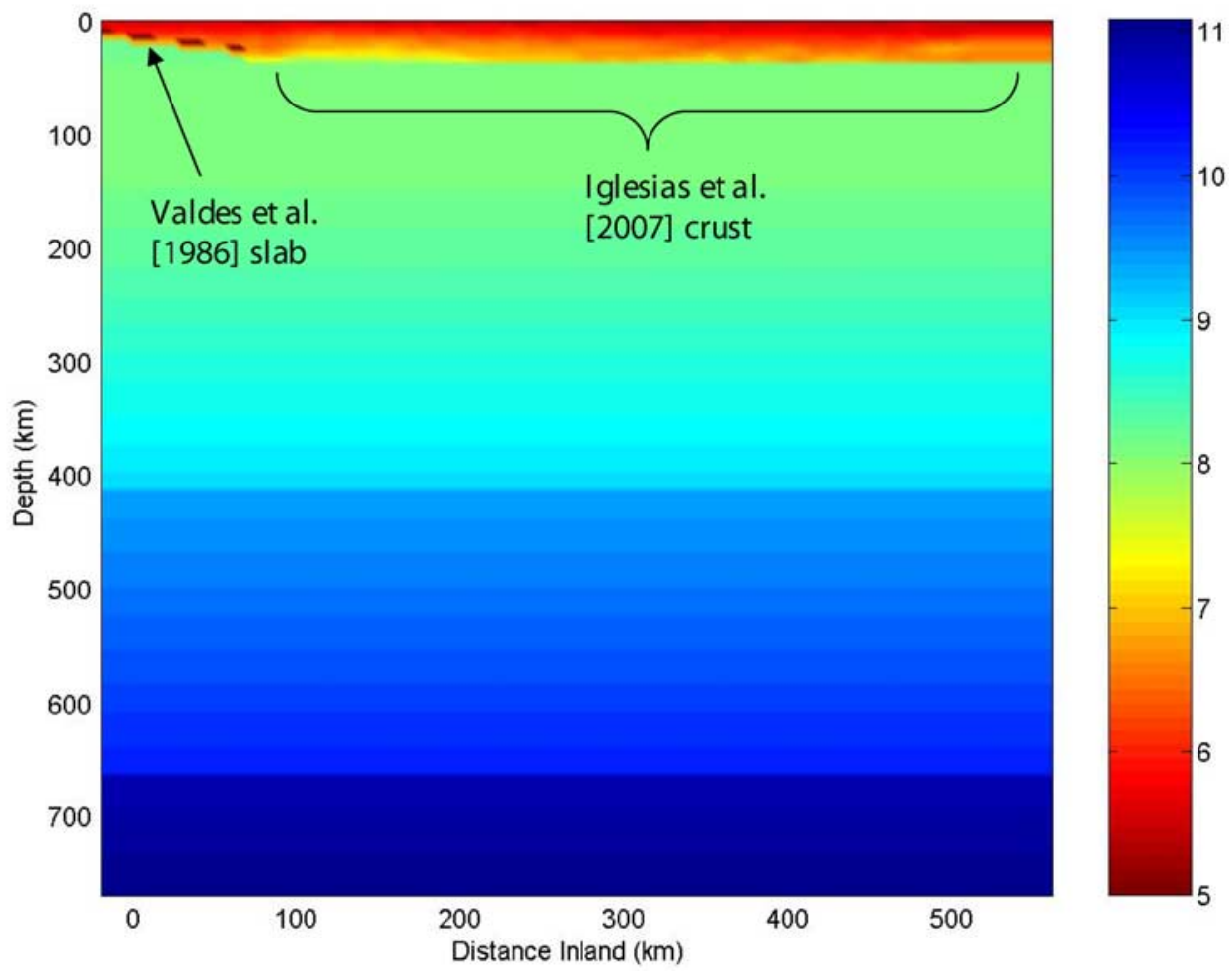

Figure 2. Complete velocity model used for ray tracing from Valdes et al. [1986] and A. Iglesias et al. (unpublished data, 2007). Color axis is $\mathrm{P}$ wave velocity $\left(\mathrm{km} \mathrm{s}^{-1}\right)$.

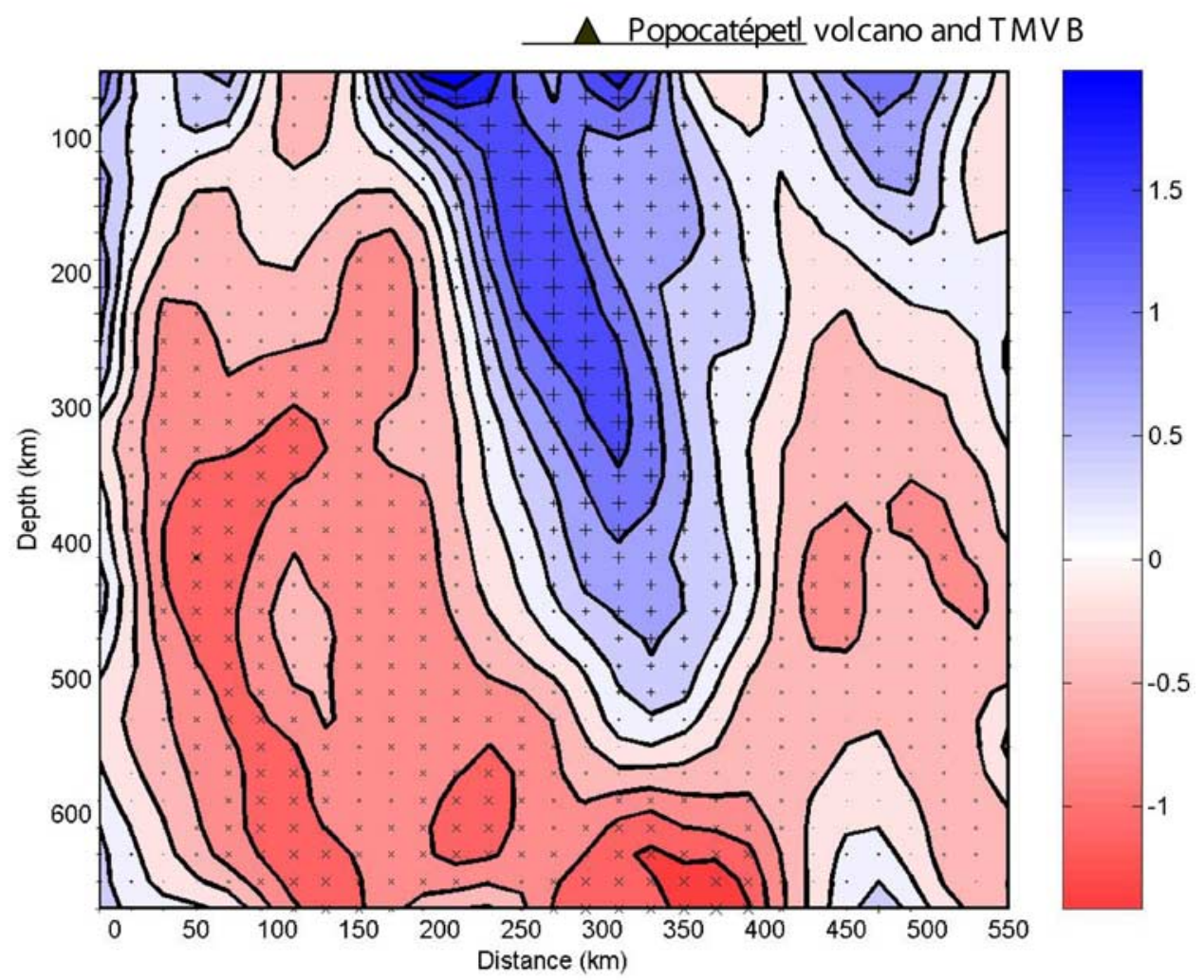

Figure 3. $\mathrm{P}$ wave velocity tomography accounting for topography. Colors are percentage of $\mathrm{P}$ velocity perturbation to the iasp91 background model [Kennett and Engdahl, 1991]. Positive grid points are marked with pluses, and negative grid points are marked with crosses. The horizontal distance is from Acapulco and runs inland. 


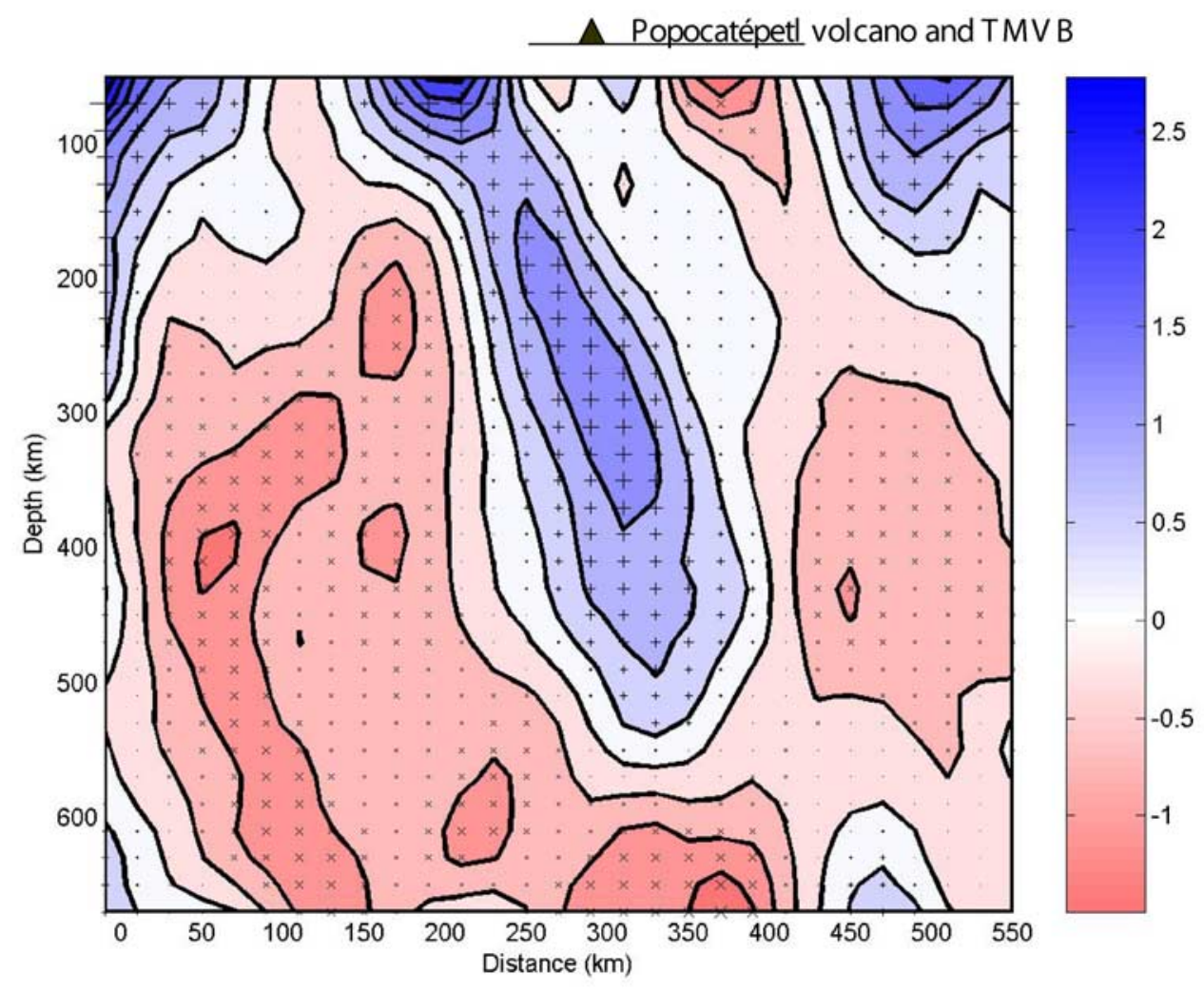

Figure 4. $\mathrm{P}$ wave velocity tomography not accounting for topography. Colors are percentage of $\mathrm{P}$ velocity perturbation to the iasp91 background model [Kennett and Engdahl, 1991]. Positive grid points are marked with pluses, and negative grid points are marked with crosses. The horizontal distance is from Acapulco and runs inland.

that regions above sea level have the same velocity as the top layer of the crustal model. The blue, fast velocity perturbation seen in the middle of the image is the Cocos slab. Figure 4 is the tomogram without a topographic correction. In the inversion with the topography correction (Figure 3), the leading edge of the slab extends into the TMVB, below the active volcano, Popocatépetl. Active volcanoes are found above the slab when it is 72 to $173 \mathrm{~km}$ depth and on average $105 \mathrm{~km}$ depth [Syracuse and Abers, 2006]. When the topography is not included in the inversion, the slab appears to have a more realistic shape near the surface; for example, low velocities occur beneath the volcanic belt. The leading edge of the slab turns to dive into the mantle at about $250 \mathrm{~km}$ inland from Acapulco (Figure 4). The high velocity (Figure 3 ) under the volcanic belt could be due to the wrong crustal model. A magnetotullric study along the same profile as MASE [Jödicke et al., 2006] revealed a low resistance anomaly deep in the crust beneath the TMVB which corresponded to the expected magmatic zone above the subducting slab. There was also a high resistance zone in the shallow crust above this anomaly at the same latitude of high-velocity anomaly shown in Figure 3. It is unclear why the high resistance zone exists from the study, but it would correspond to a high-velocity zone not accounted for in the surface wave velocities used to make the crustal model used in this study. This may suggest that the constant Poisson ratio used to create the $\mathrm{P}$ wave crustal model for this study was not a good assumption, but more thorough $\mathrm{P}$ and $\mathrm{S}$ wave velocity models of the crust are needed to determine this. It is not expected that the teleseismic tomography would resolve the upper $100 \mathrm{~km}$.

[11] In both Figures 3 and 4, despite differences near the top of the image, the deeper images are very similar. The slab appears as the fast velocity perturbation and extends to a depth of roughly $500-550 \mathrm{~km}$. It also has a very steep subduction angle of about $75^{\circ}$. The fast zones in the upper left corner of each image extending down to $300 \mathrm{~km}$ depth are possibly an edge effect due to the horizontal flat slab. The fast sections in the two right-hand corners are both less than $1 \%$ perturbation and probably edge effects. The negative perturbations in velocity in the slow zones are all less than $1 \%$. When inversions of forward modeling were done, similar slowness appeared even if only fast zones were included in the forward model as discussed below.

\section{Resolution of the $\mathbf{P}$ Wave Tomography}

[12] The lack of crossing raypaths is the greatest source for error in a tomographic inversion. For a single raypath a velocity perturbation seen at the surface could have occurred anywhere along it. The more crossing raypaths there are, the more the location of a velocity perturbation is 


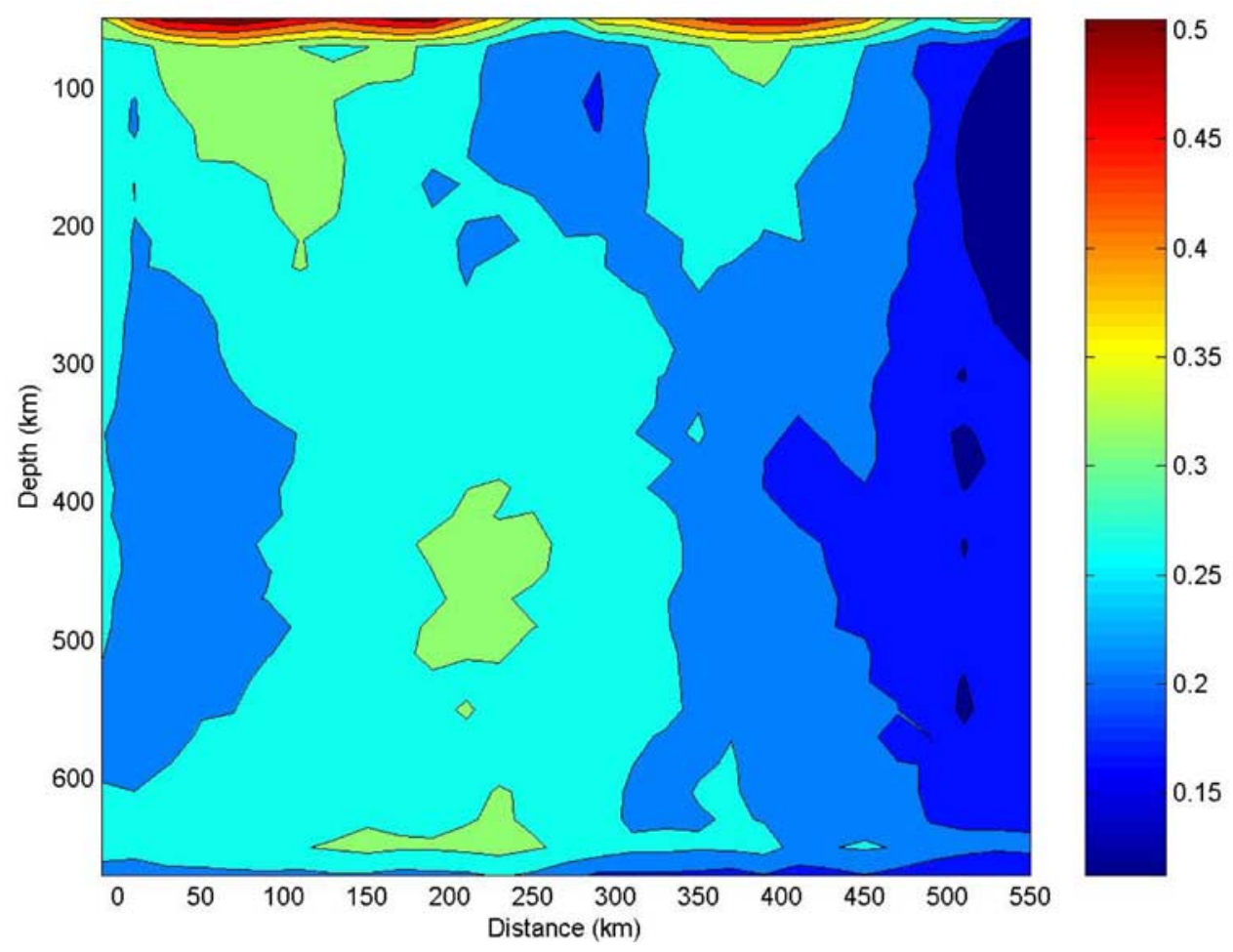

Figure 5. Diagonal of the resolution matrix at $20 \mathrm{~km} \times 20 \mathrm{~km}$ grid spacing.

constrained and greater resolution is possible. Figure 5 is the diagonal of the model resolution matrix using the inversion with $20 \mathrm{~km} \times 20 \mathrm{~km}$ spacing. Those areas with the highest resolution in Figure 5 had the highest ray coverage from the experiment. The middle and northern sections of MASE were the last to be installed, leading to the lower resolution in those regions. In addition, seismometers were moved from the north to replace broken seismometers further south toward the end of the experiment.

[13] The resolution values are a measure of how well resolved the image is, 1 being the most resolved. Values greater than 0.7 are generally viewed as acceptable. The model image is therefore not well resolved (Figure 5). Therefore, in order to generate the images with formally resolved features, a $5 \times 5$ grid point 2 -D Gaussian filter $(\sigma=16 \mathrm{~km})$ was applied after inverting. Since the tomographic images are $20 \mathrm{~km} \times 20 \mathrm{~km}$, the filter stretches over $\pm 40 \mathrm{~km}$ in each direction.

[14] In order to determine the resolution of the effective scale produced by the filter, we have reinverted the tomography at $80 \mathrm{~km} \times 80 \mathrm{~km}$ and applied no filter (Figure 6). The resolution matrix at the $80 \mathrm{~km} \times 80 \mathrm{~km}$ spacing has only a small portion below 0.7 in the upper right corner (Figure 7). We conclude that the tomography has resolution on the order of $80 \mathrm{~km} \times 80 \mathrm{~km}$. However, to avoid the "blocky" image of an $80 \mathrm{~km} \times 80 \mathrm{~km}$ grid (Figure 6), the grid space is first "oversampled" with a $20 \mathrm{~km} \times 20 \mathrm{~km}$ grid and then Gaussian filtered to its true resolution (Figures 3 and 4).

[15] Forward modeling was also done to determine what slab shapes could, in principle, be resolved with our combination of stations and events. The same rays that were used in the inversion were run through a model velocity space to generate model data. Then the model data were inverted. We used a model with a $40 \mathrm{~km}$ thick flat slab where the leading edge turns to a $75^{\circ}$ dip at $250 \mathrm{~km}$ inland with a $3 \%$ perturbation from the background model (Figure 8). The slab model was truncated at $500 \mathrm{~km}$ depth to mimic the slab found in the inversion (Figures 3 and 4). Figure 9 shows the result of the inversion from the model. A number of other forward models truncated at different depths and with different model spaces were inverted. The results of all were similar. In this particular model space, slabs that cutoff below $600 \mathrm{~km}$ smear to the bottom. Had the tomogram cutoff below $600 \mathrm{~km}$ depth, we would have extended the model space deeper. We chose to exhibit the forward model most similar to the actual tomogram.

[16] The position and shape of the slab from the inversion in Figure 9 were mostly correct, but there were a few notable incorrect parts of the model inversion. The horizontal, flat slab portion was not seen. The amplitudes were also incorrect. The areas that should have been $0 \%$ velocity perturbation showed up to $-0.5 \%$ perturbations. The relative strength of the velocity perturbation within the slab area was reduced from $3 \%$ to $2 \%$ because of the smearing of the image. In addition, the fastness extended away from the tip of the slab.

[17] A forward model with a continuous slab was inverted for as well (Figure 10). The slab continues infinitely outside of the region and the few rays outside of the image space at the depth of the slab pass through it. However, those rays are less than a few 10 s of kilometers outside the space. We show a slab with a $45^{\circ}$ dip in this example in order to exhibit how a continuous slab may have connected with the Farallon plate that van der Lee and Nolet [1997] and 


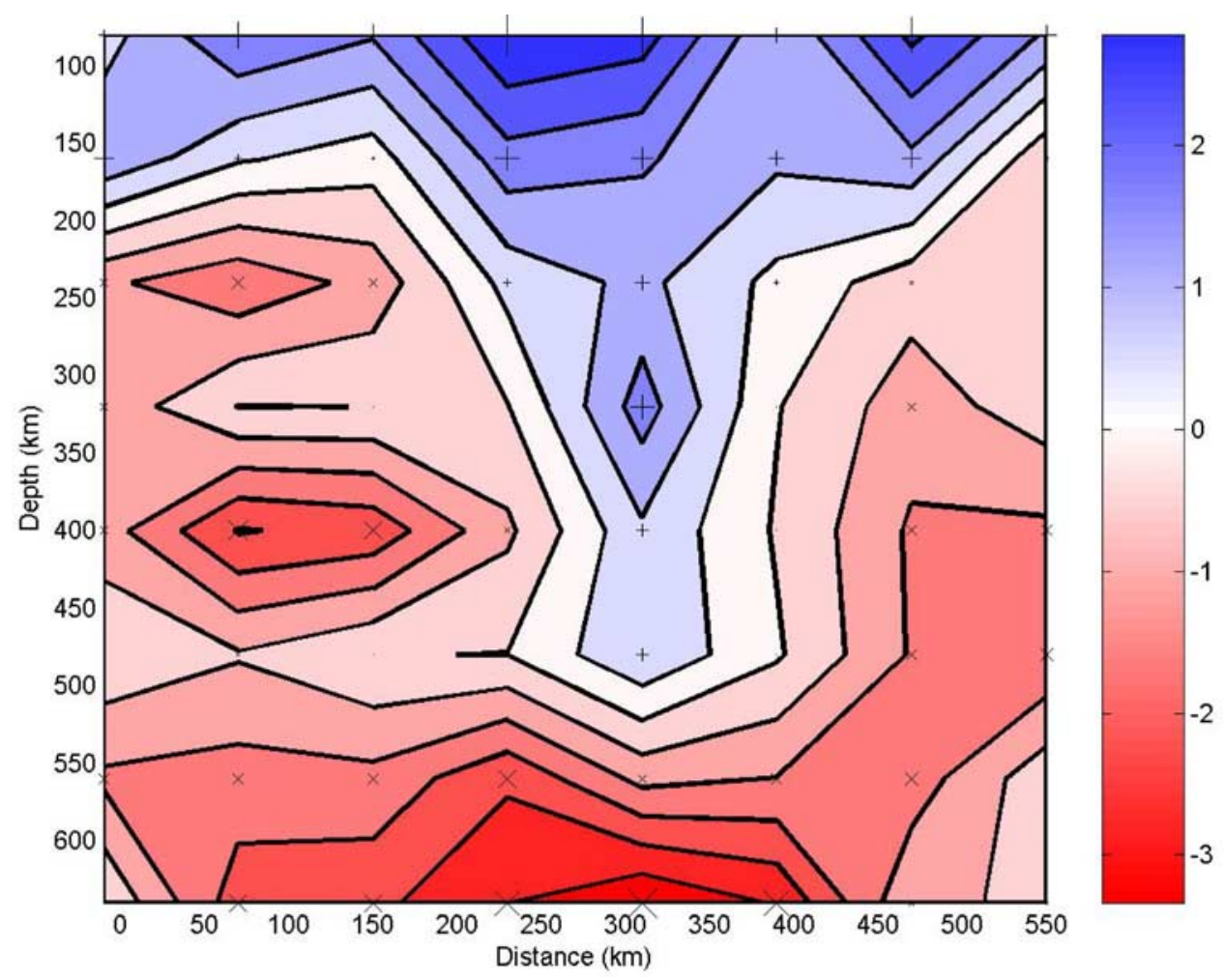

Figure 6. Tomography with an $80 \mathrm{~km} \times 80 \mathrm{~km}$ grid spacing and no 2-D Gaussian smoothing filter. Note that the depth was changed to $80 \mathrm{~km}$ to $640 \mathrm{~km}$ to accommodate the $80 \mathrm{~km} \times 80 \mathrm{~km}$ spacing.

Gorbatov and Fukao [2005] found to be near $350 \mathrm{~km}$ depth approximately $500 \mathrm{~km}$ inland. The resulting inversion of the forward model from a continuous slab (Figure 11) bears no resemblance to the tomography inverted from the data
(Figures 3 and 4) providing corroboration that the slab is not continuous. The position of the slab (Figure 11) is less accurate than for the truncated slab (Figure 9). The tomographic image of the continuous slab is much steeper and

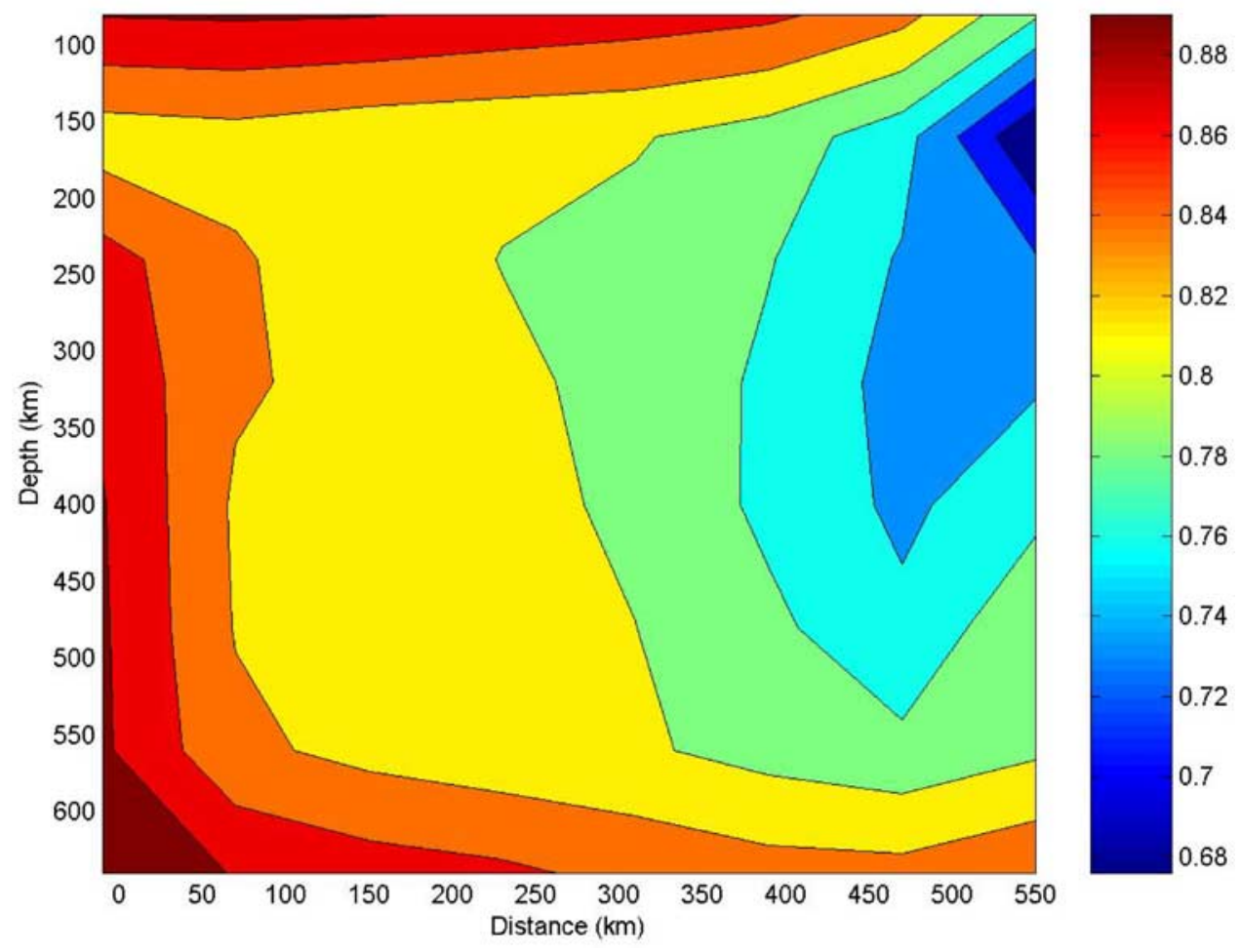

Figure 7. Resolution of the $80 \mathrm{~km} \times 80 \mathrm{~km}$ grid spaced tomographic image. 


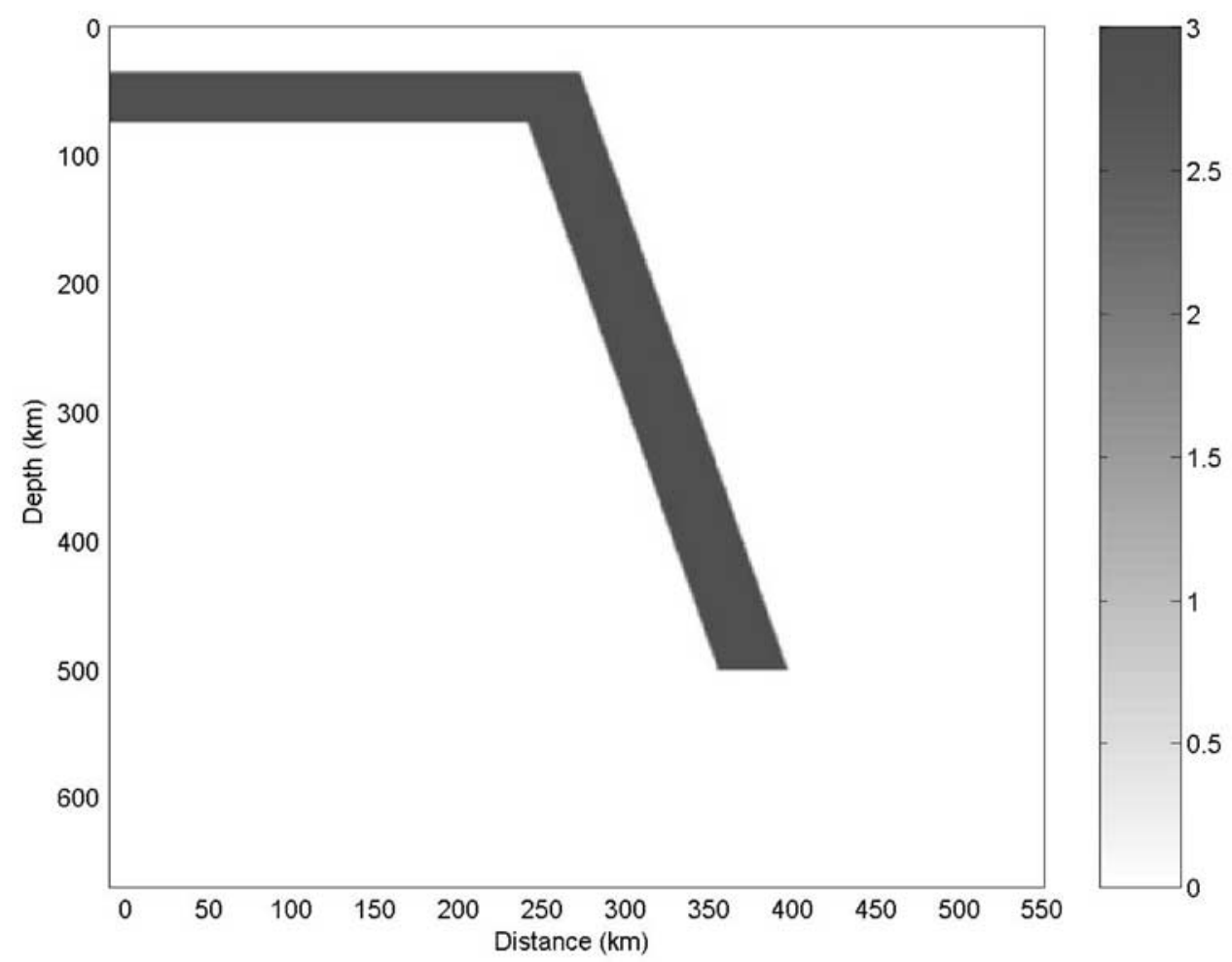

Figure 8. A 2-D forward model of the slab. The hue ranges in $\mathrm{P}$ wave velocity perturbation. The top of the image shown here goes beyond the tomography space in order to show the full extent of the slab used in the forward model.

wider than in the model. In the tomographic image of the forward model of the truncated slab, the angle of descent was more accurate and even though the slab was wider than the model, the difference was not so strong.
[18] The artifacts found in the forward modeling allowed for a better interpretation of Figures 3 and 4. The forward model had no fast velocity perturbations in the upper left corner such as those seen in the inversions of the data

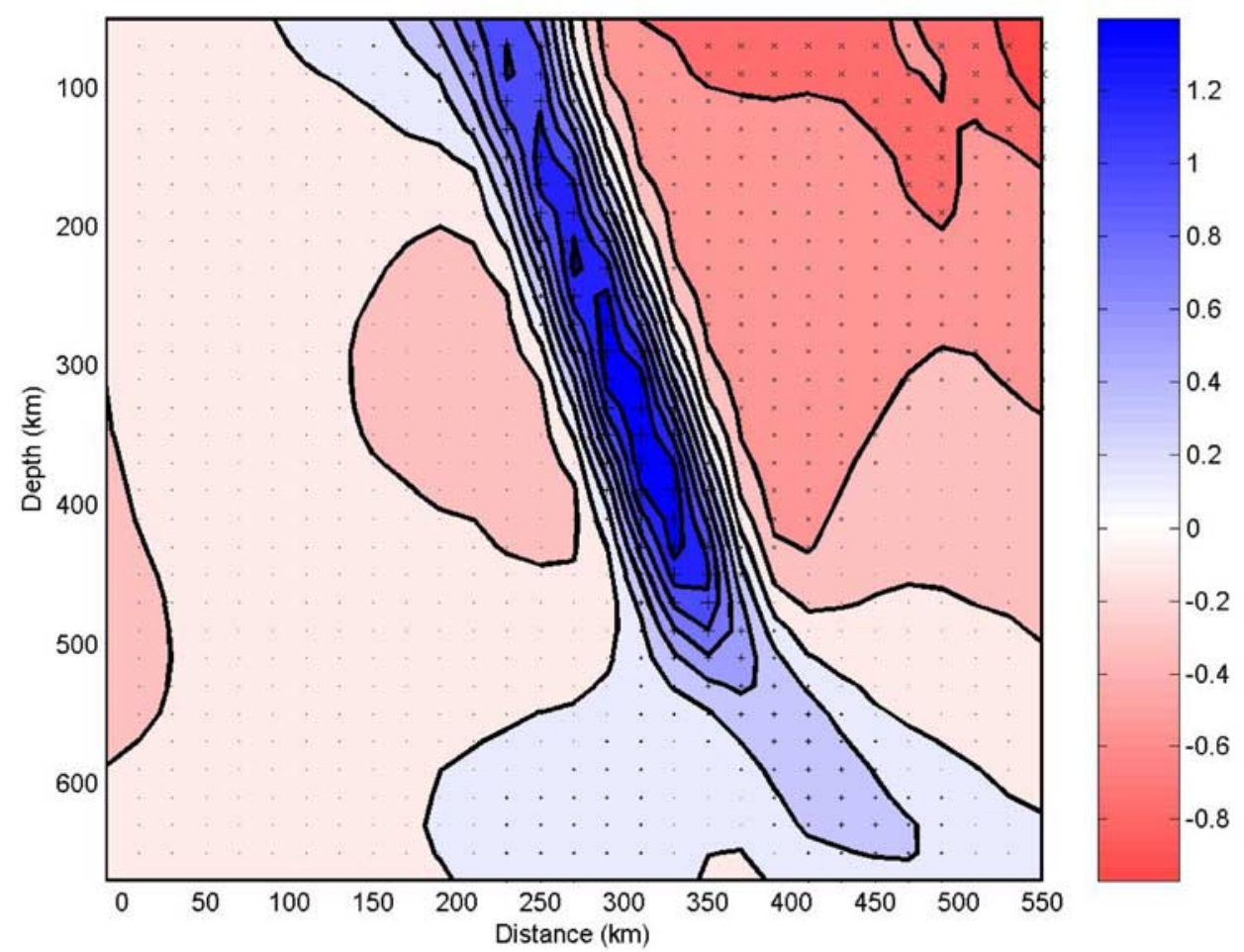

Figure 9. Inversion of the forward model shown in Figure 8. 


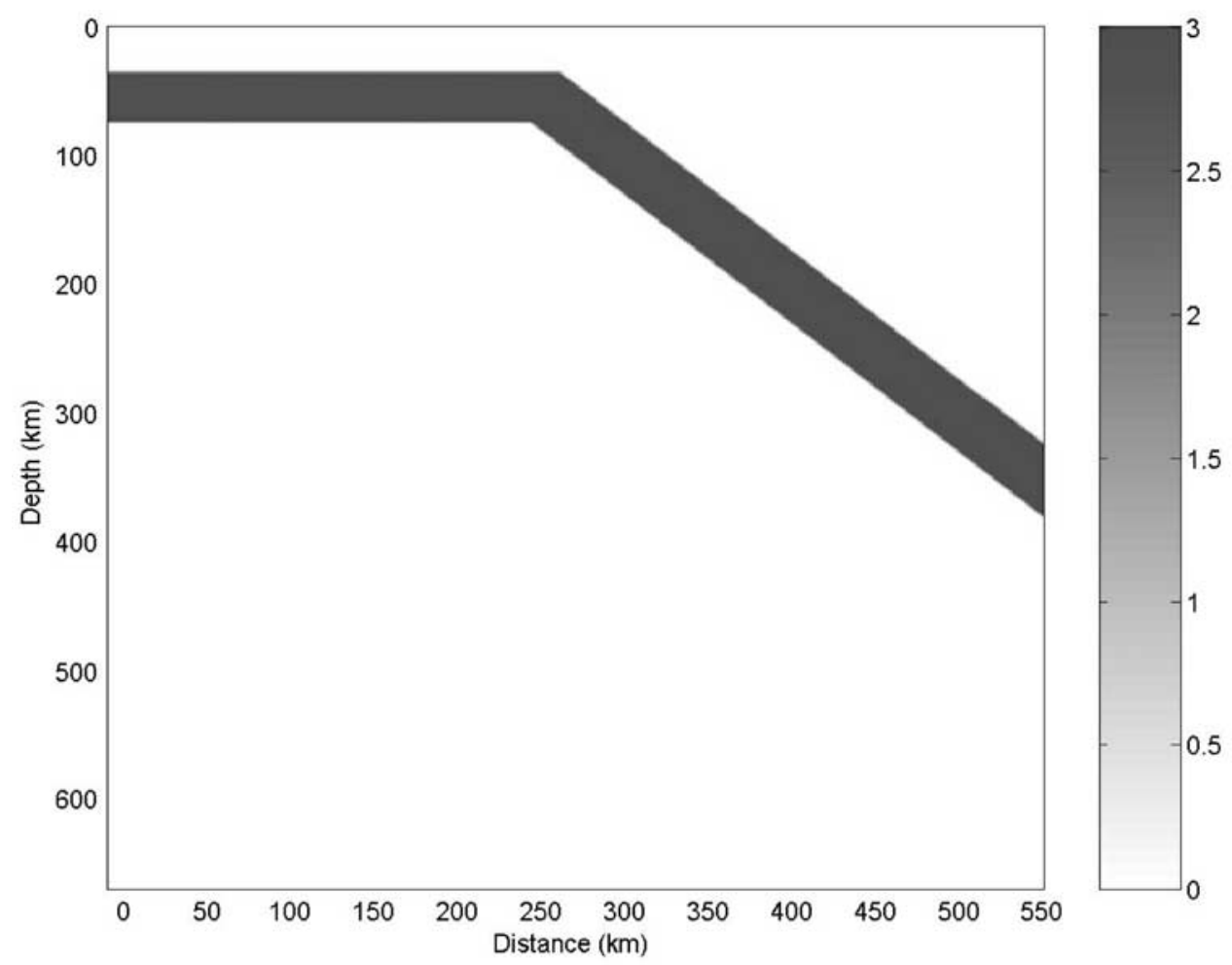

Figure 10. Forward model with continuous slab sinking at $45^{\circ}$. The hue is percentage velocity perturbation.

(Figures 3 and 4) suggesting that the actual flat slab was probably thicker or had a greater velocity perturbation than that used in the forward model. The less than $-1 \%$ velocity perturbation in the background region around much of the slab is probably an artifact from the inversion of relative delays as similar artifacts occurred in the inversion of the forward model. Finally, the actual velocity perturbation due to the slab was most likely greater than seen in the inversion

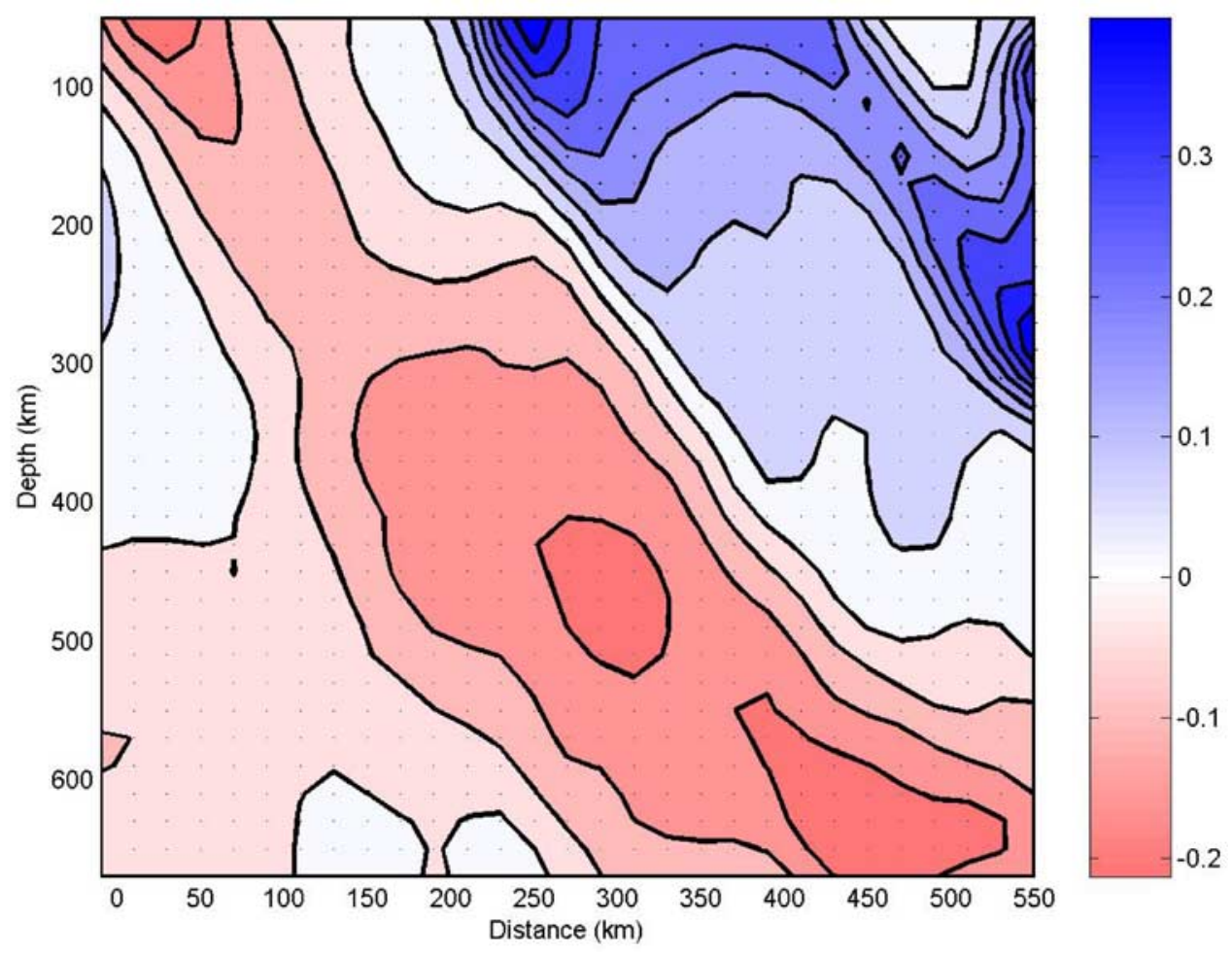

Figure 11. Inversion of model shown in Figure 10. 


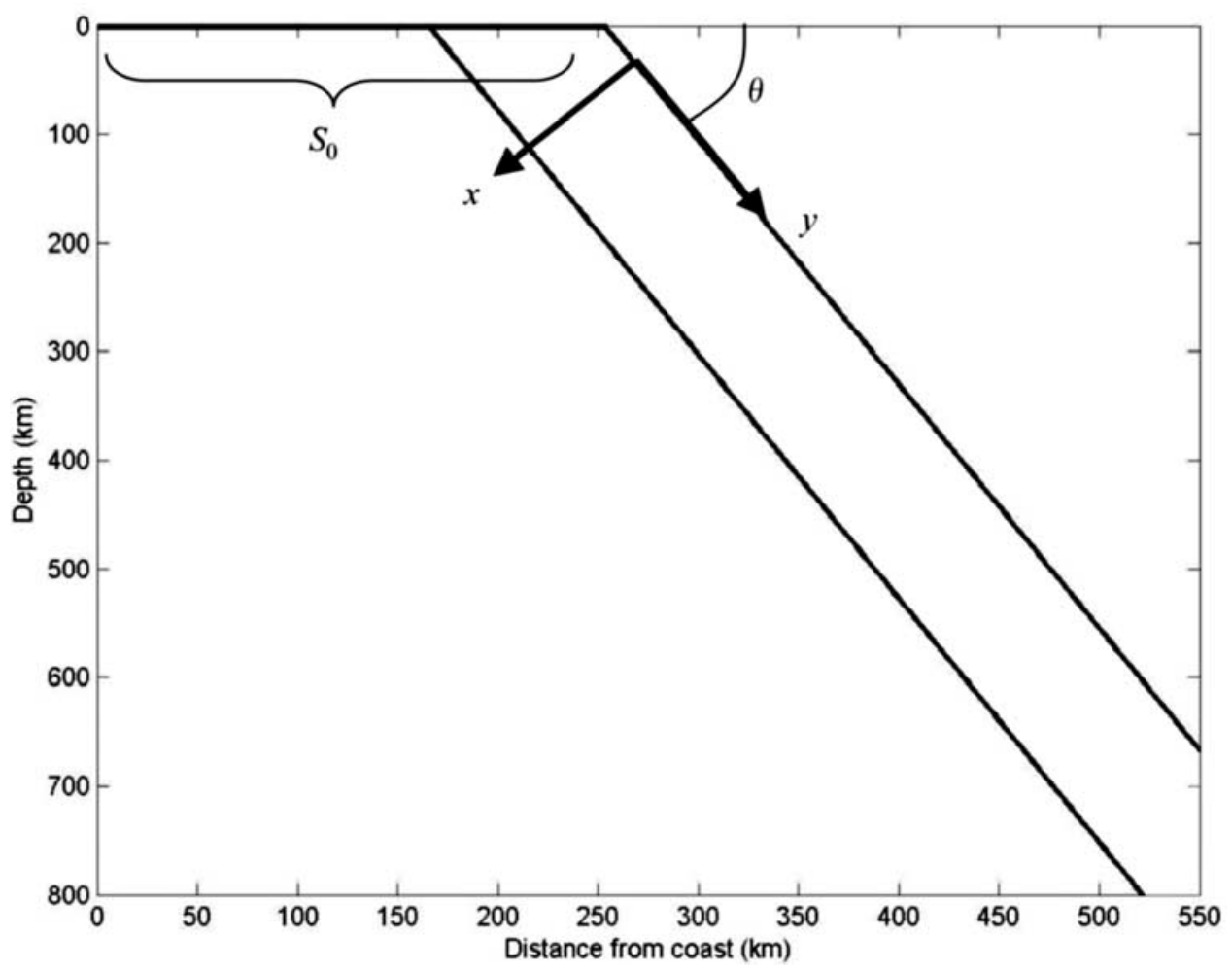

Figure 12. Coordinate system of temperature profile.

as also observed by Hearn and Clayton [1986] in southern California for example.

\section{Temperature Model}

[19] As an alternative to the block inversions of the previous section we used the travel time data to invert for the sparse parameterization that describes a slab temperature model. The benefit of a limited parameter slab model is the inversion gives well-defined slab dimensions and reduces the covariance with other blocks in the mantle. The disadvantage is if there is a lateral variation away from the slab it is not modeled and may affect the slab parameters. In addition, we apply a very basic model for fast inversions, which does not include radiogenic heat generation, frictional heating between the lower and upper plates, or torque due to bending of the slab as do more thorough thermal models of the Mexican subduction zone [i.e., Manea et al., 2005, 2006]. However, as will be shown, our results are comparable to those models and the values of primary importance to this study, the position and dip of the Cocos slab, are within the resolution of the results from tomography (Figures 3 and 4).

[20] The temperature model is derived from the diffusion equation:

$$
\frac{\partial T}{\partial t}+v \nabla T=\kappa \nabla^{2} T
$$

where $T$ is the temperature, $t$ is time, $v$ is the velocity of material with a temperature difference within the medium, and $\kappa$ is the heat diffusivity. Equation (1) is valid for spatially uniform isotropic diffusivity. We used the same 2-D slab coordinate system as Deal et al. [1999]. The origin lies on the top edge of the slab at $50 \mathrm{~km}$ depth. We chose $50 \mathrm{~km}$ depth because the receiver function study by PérezCampos et al. [2008] showed the top of the flat slab is near that depth. The $y$ axis lies along the top of the slab. The $x$ axis extends from the top of the slab into the slab and mantle (Figure 12).

[21] We assume the temperature profile is quasi-steady state; that is, the partial time derivative of the temperature in equation (1) is zero. This assumption implies the negative thermal source at the surface corresponding to the subducting slab is held at steady state if the age of the seafloor at the trench does not change over time, which is not the case for the East Pacific Rise and the trench, but we follow the assumption for the derivation keeping in mind the overly simplified model in the analysis of the results. Thus, the diffusion is due to the steady state source at the surface, plunging into the mantle in the $y$ direction with temperature spreading in the $x$ direction. Then equation (1) becomes

$$
v_{y} \frac{\partial T}{\partial y}=\kappa \frac{\partial^{2} T}{\partial x^{2}}
$$

where $v_{y}$ is the velocity of the slab as it descends into the mantle. The initial conditions are that at $y=0$, outside of the slab $(x<0$ and $h<x) T=T_{1}$, the background temperature of the mantle, where $h$ is the height of the slab. Inside the slab $(0 \leq x \leq h)$ the temperature changes linearly across the slab 

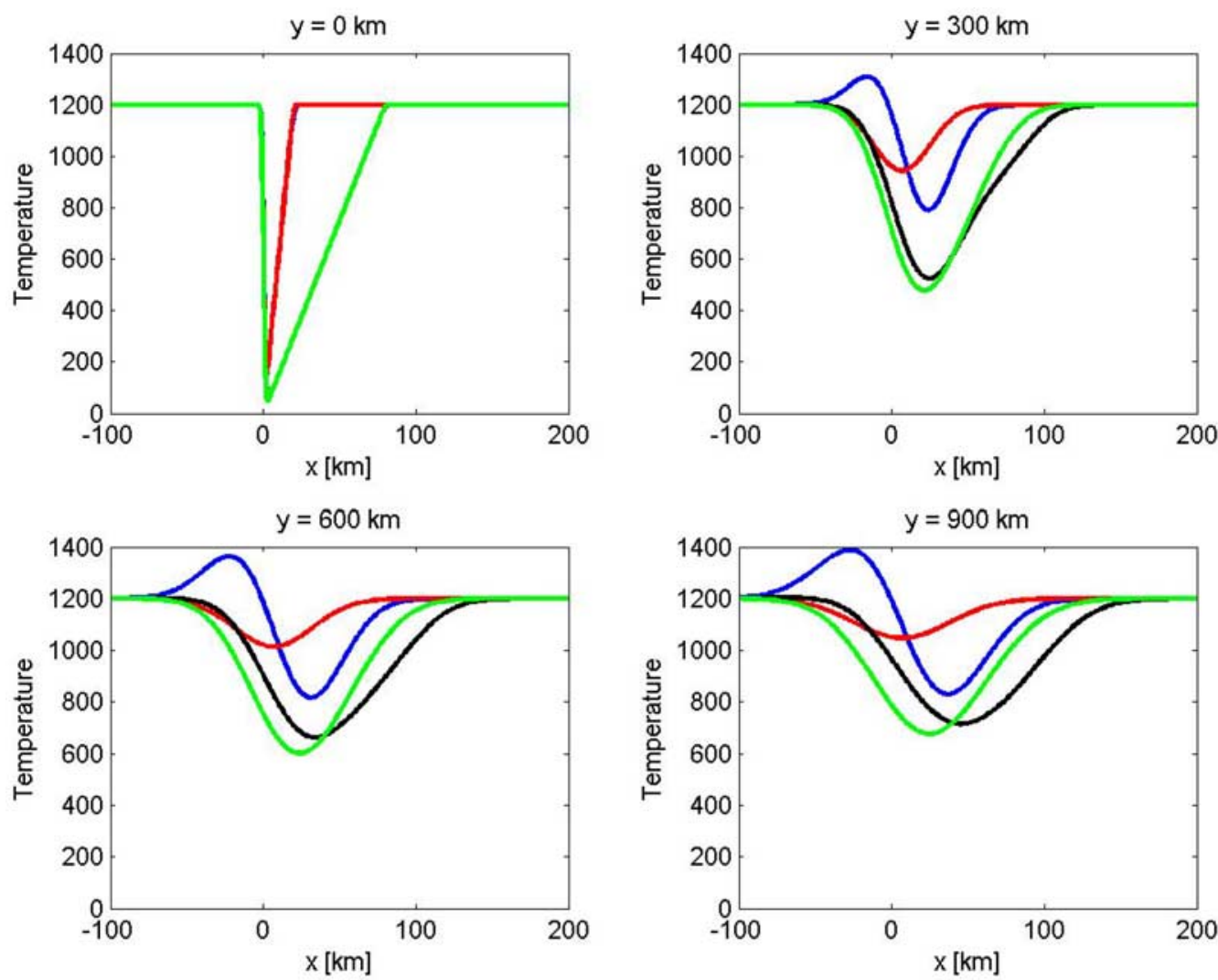

Figure 13. Temperature profiles from equation (3) in blue assuming a $20 \mathrm{~km}$ width and in black assuming an $80 \mathrm{~km}$ width for the slab. The solution goes to infinity when $\mathrm{y}=0$, so it starts at $1 \mathrm{~km}$ and continues in $300 \mathrm{~km}$ steps. Temperature profiles using equation (4) are red and green, respectively.

from $T_{0}$ at $x=0$ to $T_{1}$ at $x=h$. Deal et al. [1999] used Davies and Stevenson's [1992, Appendix A.2] solution:

$$
\begin{aligned}
T= & T_{1}+\left(T_{1}-T_{0}\right) \\
& \cdot\left(\frac{x-h}{2 h}[\operatorname{erf}(b)-\operatorname{erf}(a)]-\alpha \frac{e^{-b^{2}}-e^{-a^{2}}}{h \sqrt{\pi}}\right)
\end{aligned}
$$

where $a=-x / \alpha, b=-(x-h) / \alpha$, and $\alpha=\sqrt{(4 \kappa y) / v_{y}}$. We found that the solution appeared to be reasonable as long as $y \ll h$, but in the case of a thin slab, equation (3) gives temperatures greater than $T_{1}$ (Figure 13). Values greater than $T_{1}$ are thermodynamically impossible in a diffusion equation with starting conditions only at $T_{1}$ or below. The thinner the model slab in equation (3), the larger the region was with temperatures greater than $T_{1}$ (Figure 13). This error affected our inversion by causing the slab to have positive and negative slowness that partially canceled and are unrealistic.

[22] The steps to obtain the solution are not given by Davies and Stevenson [1992]. Since the error has propagated into several publications of which we are aware the derivation is shown in Appendix A using the same notation and coordinate system as already described. It turns out that equation (3) is missing a factor of 2 in the denominator of the last term. The solution from Appendix A is repeated here as equation (4):

$$
\begin{aligned}
T= & T_{1}+\left(T_{1}-T_{0}\right) \\
& \cdot\left(\frac{x-h}{2 h}[\operatorname{erf}(b)-\operatorname{erf}(a)]-\alpha \frac{e^{-b^{2}}-e^{-a^{2}}}{2 h \sqrt{\pi}}\right) .
\end{aligned}
$$

Equation (4) is the same as equation (3) (the solution given by Davies and Stevenson [1992]) except for a factor of $1 / 2$ missing from the last term. The error was repeated by Deal et al. [1999] and Deal and Nolet [1999]. Equation (4) is the temperature model used in all of the following inversions in this article. The $T$ obtained from equation (4) does not unrealistically rise above $T_{1}$ as equation (3) does (Figure 13). Another important item to note is the position of the slab given by equation (3) at depth along the $x$ axis is wrong. Deal et al. [1999] and Deal and Nolet [1999] found slab thicknesses between 80 and $90 \mathrm{~km}$. Thicker slabs do not exhibit as strong a difference between the results from equations (3) and (4) (Figure 13). Nonetheless at $y=900 \mathrm{~km}$ an $80 \mathrm{~km}$ thick slab is skewed more than $20 \mathrm{~km}$ in the positive $x$ direction with the incorrect equation (equation (3)).

[23] Deal et al. [1999] and Deal and Nolet [1999] avoided accounting for phase changes by inverting for the slab to $350 \mathrm{~km}$ and then resuming at $450 \mathrm{~km}$. The iasp91 
Table 1. Results From the Inversion of the Thermal Model

\begin{tabular}{lcc}
\hline & $2-\mathrm{D}$ & $2.5-\mathrm{D}$ \\
\hline$h(\mathrm{~km})$ & $40.24 \pm 0.54$ & $40.97 \pm 0.53$ \\
$\theta(\mathrm{deg})$ & $73.91 \pm 0.06$ & $74.67 \pm 0.05$ \\
$S_{0}(\mathrm{~km})$ & $232.73 \pm 0.32$ & $243.23 \pm 0.28$ \\
$y_{c}(\mathrm{~km})$ & $520.19 \pm 5.08$ & $506.91 \pm 4.68$ \\
$\varphi(\mathrm{deg})$ & Not applicable & $6.66 \pm 0.05$ \\
\hline
\end{tabular}

velocity model has a $3 \%$ jump in velocity at $410 \mathrm{~km}$ depth [Kennett and Engdahl, 1991] where olivine goes to wadsleyite. The iasp91 velocity model has no change when olivine goes to ringwoodite at $520 \mathrm{~km}$ [Kennett and Engdahl, 1991] so ignoring that phase change is valid as it does not have a strong effect on seismic velocity. The elevation of the $410 \mathrm{~km}$ phase change from the lower temperatures caused by the slab can be adjusted using Turcotte and Schubert's [2002, p. 191] value of the change in the depth of the phase change due to temperature differences within the slab, $d Z / d T=0.055 \mathrm{~km} \mathrm{~K}^{-1}$. Hence,

$$
Z=410-\left(T_{1}-T\right) \frac{d Z}{d T} .
$$

The net effect is a broad-scale $\sim 22 \mathrm{~km}$ maximum elevation of the 410 discontinuity over about $50 \mathrm{~km}$ that corresponds to an area less than 2 grid points within the tomography of the previous sections (Figures 3 and 4). This effect adds to the increased velocity due to lower temperature but over this restricted area the overall effect is not significant and therefore not included in the final model.

[24] In order to measure the effect of the temperature model on arrival times, the model is converted to velocity using a modified version of the equation used by Deal et al. [1999]:

$$
\Delta V=D(y)\left(T_{1}-T\right) \frac{d V}{d T},
$$

where $\Delta V$ is the velocity, $d V / d T=4.8 \times 10^{-4} \mathrm{~km} \mathrm{~s}^{-1}{ }^{\circ} \mathrm{C}^{-1}$ as used by Deal et al. [1999]. $D(y)$ is a nondimensional depth truncation factor that we chose to account for a truncated slab:

$$
D(y)=\frac{1}{\pi}\left(\frac{\pi}{2}-\arctan \left(y-y_{c}\right)\right),
$$

where $y_{c}$ is distance down the slab of the cutoff or truncation. A continuous function was used to truncate the slab in order to be able to use the least squares method to find the truncation location.

[25] The initial conditions are an approximation because the slab travels $250 \mathrm{~km}$ in flat subduction before it plunges into the mantle. We did not approximate the effects of heating the top of the flat slab by the bottom of the crust which is better approximated as a transient rather than steady state problem. However, given that the slab spends only about $4 \mathrm{Ma}$ in the flat configuration assuming the present rate of subduction, the double ramp temperature corresponding to a linear geotherm in the crust and slab is blunted by diffusion. Still the initial conditions for the steep descent are reasonably well approximated by equation (4).

\section{Inversion of the Temperature Model}

[26] The data were inverted to obtain the temperature model by running all of the rays through it and summing the travel times due to perturbations from the temperature model. The travel times were then inverted to find slab parameters using the nonlinear damped least squares method [e.g., Bevington and Robinson, 2003]. Previously, we had found that a few percent velocity change did not affect the ray positions enough to require the rays to be recomputed. Hence the rays were precomputed from the iasp91 velocity model [Kennett and Engdahl, 1991] to speed the inversion, but it was still quite slow $(\sim 2 \mathrm{~h})$.

[27] The model consists of a flat slab and a dipping portion both with slab thickness, $h$. The location of the point of descent is $S_{0}$. The flat region was held to the $y=0$ starting parameters, which is an approximation, but as was shown in the tomography (Figures 3 and 4), the teleseismic rays are highly insensitive to its properties. The variables solved for were the thickness of the slab, $h$, the angle of descent, $\theta$, the point of descent from the top of the slab, $S_{0}$, and the distance down the slab of truncation, $y_{c} . S_{0}$ is the distance from the coast where the slab changes from flat slab subduction to descend into the mantle. As mentioned previously, the depth to the top of the slab at $S_{0}$ was fixed at $50 \mathrm{~km} . T_{1}$ and $T_{0}$ were held constant and set to $1200^{\circ} \mathrm{C}$ and $0^{\circ} \mathrm{C}$, respectively.

[28] The strike of the slab from north was solved for by assuming the 2-D model extended infinitely along the $z$ axis. The slab was allowed to rotate about the point of descent where the axis of rotation was the normal to the surface of the Earth. The solution only added one degree of freedom, but used the entire 3-D raypaths, so it was labeled the $21 / 2-\mathrm{D}$ inversion.

[29] Table 1 lists the results of both the 2-D and the 2 1/2-D inversion. The solution for the strike of the slab is listed in terms of the angle between the strike of the MASE array and the normal to the strike of the slab. This is because the strike of the MASE array is nearly perpendicular to the trench in Acapulco. The angle between the array and the normal to the strike of the slab gives a good correlation to the angle between the strike of the trench and the strike of the slab.

[30] The results are so similar in Table 1 that we only show the 2-D model in Figure 14. The 2-D position and shape of the slab agree well with the tomography (Figures 3 and 4). The major difference is that the amplitudes of the flat slab are lower in the tomogram. The results of the thermal model can also be compared to those of more detailed thermal models of the 2-D profile [Manea et al., 2005, 2006]. Unlike those thermal models, our model is limited to temperatures within the slab. Within the slab our isothermal contours extend to

Figure 14. (top) The velocity perturbation due to the temperature model solved for in the inversion. The contours are in terms of percentage of velocity perturbation to the background model. (bottom) The temperature model solved for in the inversion. The contours are ${ }^{\circ} \mathrm{K}$. 

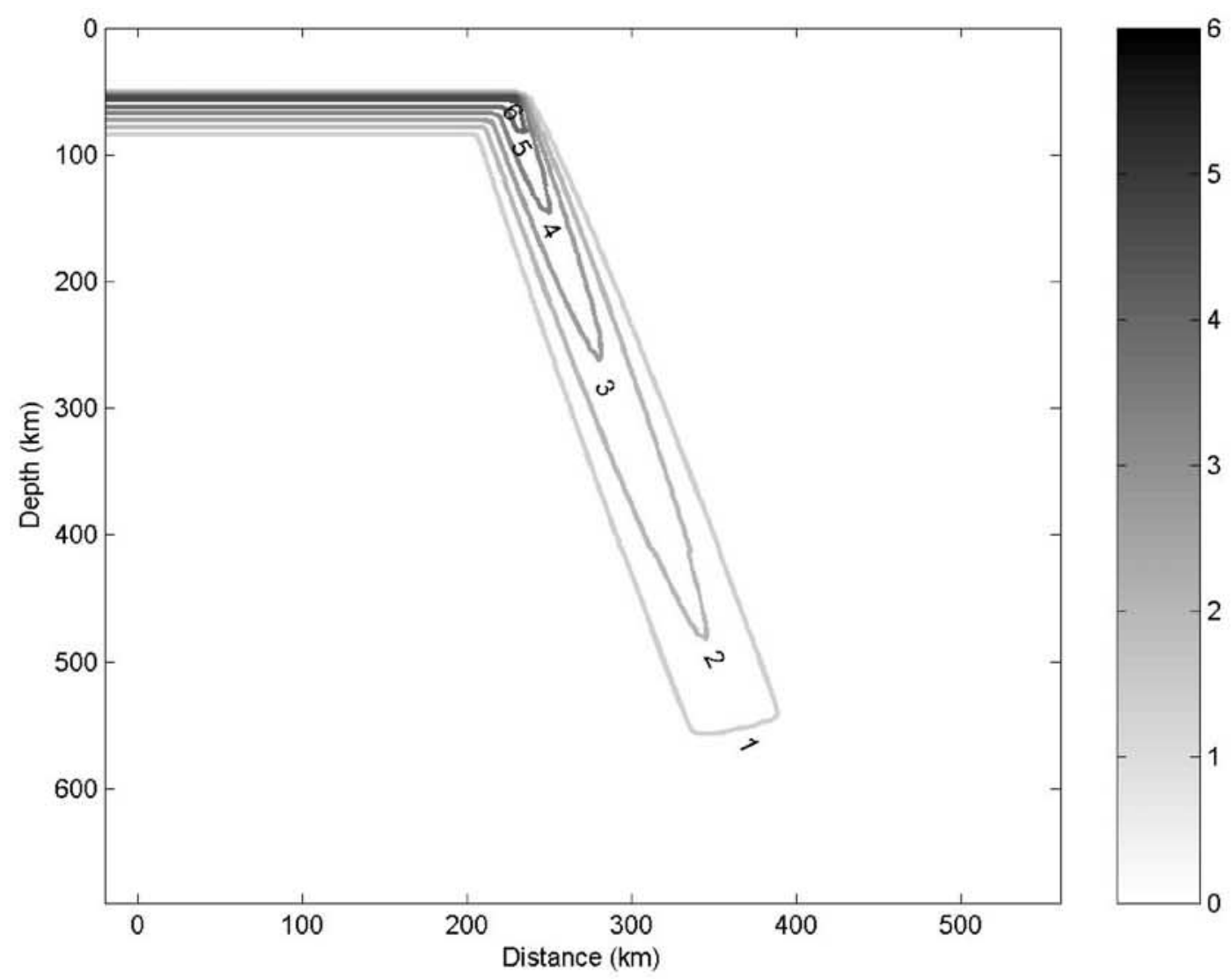

5
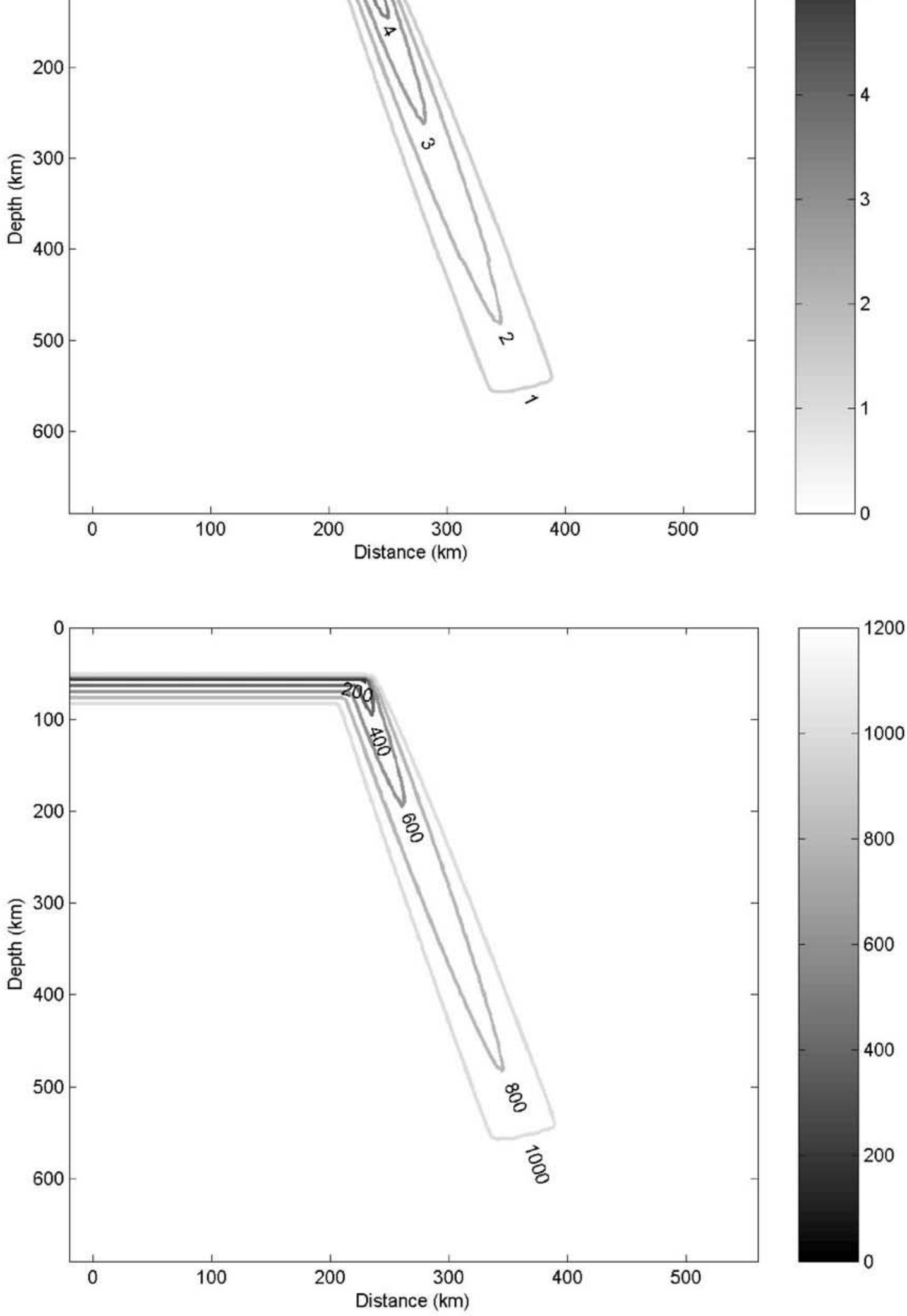

Figure 14

12 of 15 


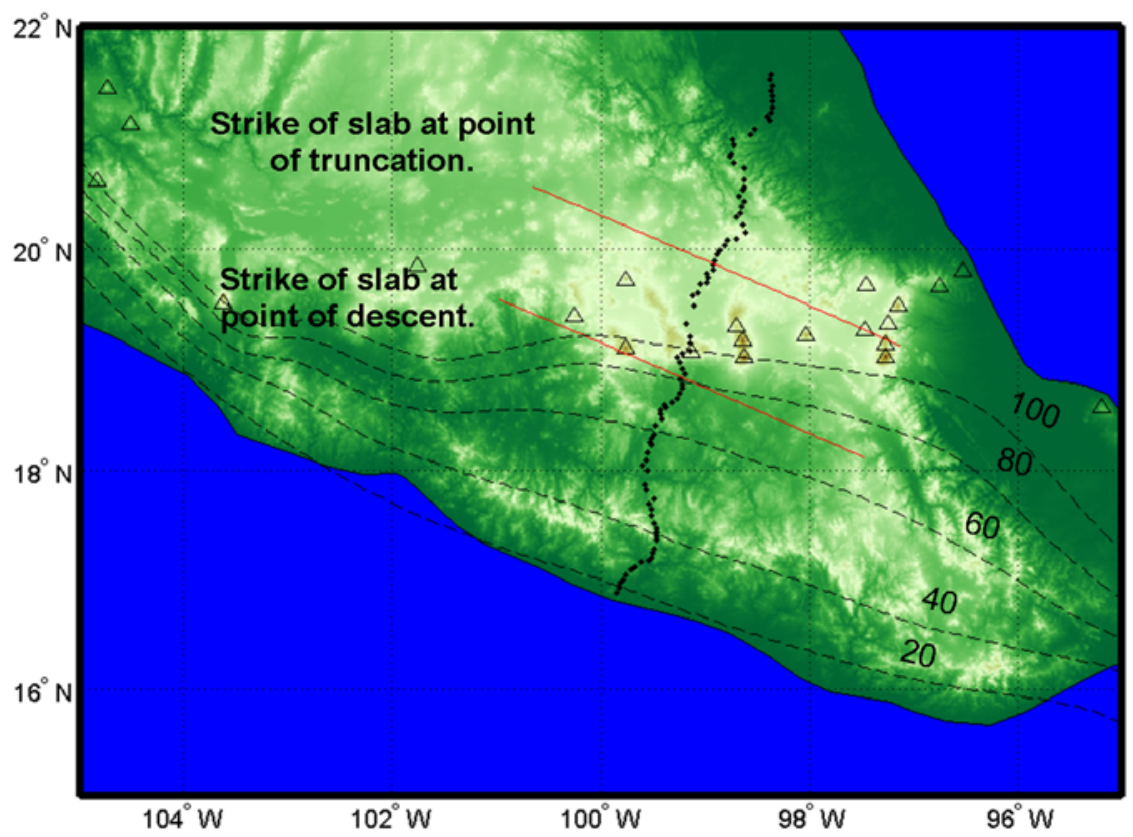

Figure 15. Map view of the strike and location of the slab determined from the inversion.

greater depths than those of Manea et al. [2005]. This is most likely due to assuming a $1200^{\circ} \mathrm{C}$ background mantle temperature following Deal et al. [1999], unlike the $1400^{\circ} \mathrm{C}$ mantle temperature assumed by Manea et al. [2005]. In addition, the flat section of the slab in our model has no complexity such as that due to torque [Manea et al., 2006]. However, the nearly vertical rays that pass through the region encounter the same restrictions as a standard tomography and would not be able to resolve anything complex there had we attempted to model it. Finally, we find a much more steeply dipping slab $\left(75^{\circ}\right)$ and greater distance from the coast $(\sim 235 \mathrm{~km})$ than that assumed in the more complex models $\left(20^{\circ}\right.$ and $\sim 200 \mathrm{~km}$, respectively) [Manea et al., 2005, 2006], however they had no direct evidence for either as there is no Wadati-Benioff zone.

[31] The map view position of the strike of the slab is shown in Figure 15 as well as the depth contours determined from seismicity [Pardo and Suarez, 1995]. The strike of subduction, nearly perpendicular to the MASE seismic line as determined in the inversion, follows the seismicity depth contours. The strike of the truncation is probably different from that of the strike of the slab at the point of descent, as inferred from the depth contours and the TMVB; however, our simple 2 1/2-D model cannot take this into account.

\section{Summary and Conclusions}

[32] The goal of this study was to determine the location of the subducting Cocos plate beneath the Trans-Mexican Volcanic Belt (TMVB), whether it is truncated or continuous and to estimate its thermal state. Previous regional tomography [Gorbatov and Fukao, 2005] imaged a continuous Cocos slab, but had very low resolution. A geochemical study [Ferrari, 2004] recognized the eastward migration with time of a mafic pulse of volcanism to the north of the modern TMVB (between $\sim 11$ and $\sim 5 \mathrm{Ma}$ ). This migrating mafic pulse was interpreted to reflect the lateral propagation of slab detachment initiated at $\sim 13 \mathrm{Ma}$ in the Gulf of California. This argument is now corroborated by a direct image of a truncated slab.

[33] Pardo and Suarez [1995] determined that the Cocos plate, in our study region, was subhorizontal with the top edge about $50 \mathrm{~km}$ depth until about $250 \mathrm{~km}$ inland at which point seismicity ends. They surmised that the normal focal mechanisms at this point signified a turn in the Cocos plate to continue sinking. Our tomography inversion confirmed that the slab descends at this location and continues subducting at an angle of $75^{\circ}$ to a depth of $500-550 \mathrm{~km}$.

[34] As well as a block inversion we inverted for the parameters of a slab thermal model. We were able to limit the inversion to just a few parameters including the slab position and thickness. When we accounted for the flat portion of the slab we achieved similar results to the tomography. The slab descends at an angle of $\sim 74^{\circ}$ extending 507-520 km downdip. The inverted model was extended to $21 / 2-\mathrm{D}$ by assuming the model is infinite along the strike of the slab and using the full 3-D raypaths to solve its strike. The result differs from the strike of major geological features such as the TMVB and the seismicity. At the depth of the model space the rays stay within $100 \mathrm{~km}$ of the profile. Thus, in order to extend the results laterally from the model further, the surrounding structure and tectonic setting must be used.

[35] The age of the Cocos slab at the trench near Acapulco is $13 \mathrm{Ma}$. The expected thickness of $13 \mathrm{Ma}$ old lithosphere is $54 \mathrm{~km}$ assuming a thermal diffusivity constant of $1.3 \times 10^{-6} \mathrm{~m}^{2} \mathrm{~s}^{-1}$ [Stacey, 1992]. Thermal diffusivity constants have been estimated to be as low as of $0.55 \times$ $10^{-6} \mathrm{~m}^{2} \mathrm{~s}^{-1}$ across the Indian Ridge [Doucouré and Patriat, 1992]. That low value would give a thickness of $36.2 \mathrm{~km}$ for the Cocos slab. The value of the thickness of the Cocos slab from the inversion of $40 \mathrm{~km}$ is within this range. Most estimates of (seismic) lithospheric thickness are based on depths to low-velocity zones found from surface 
wave dispersion on flat lying plates. This has been the basis for half-space and plate models of ocean floor topography [e.g., Stein and Stein, 1992]. Thus, our experiment finds that the slab thicknesses determined by body waves in the Cocos slab is consistent with the half-space cooling model.

[36] The absence of a Wadati-Benioff zone beneath Mexico City can be explained by either lack of stress or temperatures too high for brittle failure. Jackson et al. [2008] note that earthquakes in the dehydrated lithosphere of oceanic plates occur at temperatures lower than the $600^{\circ} \mathrm{C}$ isotherm. Figures 13 and 14 show that temperatures in the slab reach these levels at shallow depths as was previously found by Manea et al. [2006]. In addition, a truncated plate will have less stress from negative buoyancy than a continuous plate. Thus, earthquakes deeper than $100 \mathrm{~km}$ are not expected, as is observed.

\section{Appendix A: Solution to Diffusion Equation}

[37] We begin with the solution to equation (2) taken from Carslaw and Jaeger [1959, chapter 2.2, equation 1]

$$
T=\frac{1}{\alpha \sqrt{\pi}} \int_{-\infty}^{\infty} f\left(x^{\prime}\right) e^{-\left(x-x^{\prime}\right)^{2} / \alpha^{2}} d x^{\prime}
$$

where $T=f(x)$, when $y=0$. Carslaw and Jaeger [1959] express $\alpha$ in terms of time $(\alpha=\sqrt{4 \kappa \mathrm{t}})$. However, because of the assumption of a constant velocity of the slab, $t=y / v_{y}$ can be substituted into $\alpha$, to give $\alpha=\sqrt{(4 \kappa y) / v_{y}}$. Given the same initial conditions (at $y=0, T=T_{1}$ for $x<0$ and $h<x$, and $T=x\left(T_{1}-T_{0}\right) / h+T_{0}$ for $\left.0 \leq x \leq h\right)$, equation (A1) becomes

$$
\begin{aligned}
T= & \frac{1}{\alpha \sqrt{\pi}}\left[\int_{-\infty}^{0} T_{1} e^{-\left(x-x^{\prime}\right)^{2} / \alpha^{2}} d x^{\prime}\right. \\
& +\int_{0}^{h}\left(\left(T_{1}-T_{0}\right) \frac{x^{\prime}}{h}+T_{0}\right) e^{-\left(x-x^{\prime}\right)^{2} / \alpha^{2}} d x^{\prime} \\
& \left.+\int_{h}^{\infty} T_{1} e^{-\left(x-x^{\prime}\right)^{2} / \alpha^{2}} d x^{\prime}\right] .
\end{aligned}
$$

A change of variables is made to simplify the integral.

$$
\begin{gathered}
x^{\prime}=x+\alpha X . \\
d x^{\prime}=\alpha d X .
\end{gathered}
$$

Equations (A3) and (A4) are applied to the first term of the integral from equation (A2), and the term is solved for (equation (A2) first term)

$$
\begin{aligned}
\frac{T_{1}}{\sqrt{\pi}} \int_{-\infty}^{a} e^{-X^{2}} d X= & \frac{T_{1}}{\sqrt{\pi}} \int_{-\infty}^{a} e^{-X^{2}} d X-\frac{T_{1}}{\sqrt{\pi}} \int_{-\infty}^{\infty} e^{-X^{2}} d X \\
& +\frac{T_{1}}{\sqrt{\pi}} \int_{-\infty}^{\infty} e^{-X^{2}} d X
\end{aligned}
$$

where $a=-x / \alpha$. The first 2 integrals are added together to simplify the equation. The two integrals share a common area from $-\infty$ to $a$, but one is negative so this section of the integral cancels and only $a$ to $\infty$ is left from the second term. The third term is left untouched.

$$
-\frac{T_{1}}{\sqrt{\pi}} \int_{a}^{\infty} e^{-X^{2}} d X+\frac{T_{1}}{\sqrt{\pi}} \int_{-\infty}^{\infty} e^{-X^{2}} d X
$$

The first integral is the complimentary error function and the second integral is $\sqrt{\pi}$ :

$$
-\frac{T_{1}}{2} \operatorname{erfc}(a)+T_{1}
$$

The complimentary error function is changed to the error function (equation (A2) first term)

$$
-\frac{T_{1}}{2}+\frac{T_{1}}{2} \operatorname{erf}(a)+T_{1}
$$

It is left in this form to match the 3rd term of equation (A2). Applying equations (A3) and (A4) to the last term of equation (A2) and following the same steps as were shown for the first term of equation (A2) gives (equation (A2) third term)

$$
\frac{T_{1}}{\sqrt{\pi}} \int_{b}^{\infty} e^{-X^{2}} d X=\frac{T_{1}}{2} \operatorname{erfc}(b)=\frac{T_{1}}{2}-\frac{T_{1}}{2} \operatorname{erf}(b)
$$

where $b=-(x-h) / \alpha$. Applying equations (A3) and (A4) to the middle term of the integral from equation (A2) gives (equation (A2) second term)

$$
\begin{aligned}
& \frac{1}{\sqrt{\pi}} \int_{a}^{b}\left(\left(T_{1}-T_{0}\right) \frac{(x+\alpha X)}{h}+T_{0}\right) e^{-X^{2}} d X=\frac{1}{\sqrt{\pi}} \\
& \cdot\left[\left(\left(T_{1}-T_{0}\right) \frac{(x)}{h}+T_{0}\right) \int_{a}^{b} e^{-X^{2}} d X+\frac{\alpha\left(T_{1}-T_{0}\right)}{h} \int_{a}^{b} X e^{-X^{2}} d X\right] .
\end{aligned}
$$

(equation (A2) second term)

$$
=\frac{\left(T_{1}-T_{0}\right) x+T_{0} h}{2 h}(\operatorname{erf}(b)-\operatorname{erf}(a))-\frac{\alpha\left(T_{1}-T_{0}\right)}{2 h \sqrt{\pi}}\left(e^{-b^{2}}-e^{-a^{2}}\right) .
$$

Combining all terms together, equation (A2) becomes

$$
\begin{aligned}
T= & T_{1}-\frac{T_{1}}{2}(\operatorname{erf}(b)-\operatorname{erf}(a)) \\
& +\frac{\left(T_{1}-T_{0}\right) x+T_{0} h}{2 h}(\operatorname{erf}(b)-\operatorname{erf}(a)) \\
& -\frac{\alpha\left(T_{1}-T_{0}\right)}{2 h \sqrt{\pi}}\left(e^{-b^{2}}-e^{-a^{2}}\right) .
\end{aligned}
$$




\section{Equation (A5) reduces to}

$$
\begin{aligned}
T= & T_{1}+\left(T_{1}-T_{0}\right) \\
& \cdot\left(\frac{x-h}{2 h}[\operatorname{erf}(b)-\operatorname{erf}(a)]-\alpha \frac{e^{-b^{2}}-e^{-a^{2}}}{2 h \sqrt{\pi}}\right) .
\end{aligned}
$$

[38] Acknowledgments. This work was supported by the Tectonics Observatory at Caltech, the Center for Embedded Network Sensors (CENS) at UCLA, NSF award EAR0609707, PAPIITUNAM projects IX120004 and IN119505-3, and UC MEXUS project 04105384. The MASE experiment was funded by the Gordon and Betty Moore Foundation. Contribution 90 from the Tectonics Observatory. We thank the numerous volunteers for their many hours of field work. We also thank Luca Ferrari and another anonymous reviewer for their comments improving the article.

\section{References}

Bevington, P. R., and D. K. Robinson (2003), Data Reduction and Error Analysis for the Physical Sciences, 3rd ed., McGraw-Hill, New York.

Carslaw, H. S., and J. C. Jaeger (1959), Conduction of Heat in Solids, 2nd ed., Clarendon Press, Oxford, U. K.

Davies, J. H., and D. J. Stevenson (1992), Physical model of source region of subduction zone volcanics, J. Geophys. Res., 97, 2037-2070, doi:10.1029/91JB02571

Deal, M. M., and G. Nolet (1999), Slab temperature and thickness from seismic tomography: 2. Izu-Bonin, Japan, and Kuril subduction zones, J. Geophys. Res., 104, 28,803-28,812, doi:10.1029/1999JB900254

Deal, M. M., G. Nolet, and R. D. van der Hilst (1999), Slab temperature and thickness from seismic tomography: 1 . Method and application to Tonga, J. Geophys. Res., 104, 28,789-28,802, doi:10.1029/1999JB900255.

Doucouré, C. M., and P. Patriat (1992), Thermal diffusivity of the lithosphere derived from altimetry and bathymetry profiles across the Southwest Indian Ridge, Geophys. Res. Lett., 19, 1543-1546, doi:10.1029/92GL01736.

Ferrari, L. (2004), Slab detachment control on mafic volcanic pulse and mantle heterogeneity in central Mexico, Geology, 32, 77-80, doi:10.1130/ G19887.1.

Gorbatov, A., and Y. Fukao (2005), Tomographic search for missing link between the ancient Farallon subduction and the present Cocos subduction, Geophys. J. Int., 160, 849-854, doi:10.1111/j.1365-246X. 2005. 02507.x.

Hearn, T. M., and R. W. Clayton (1986), Lateral velocity variations in Southern California. I. Results for the upper crust from Pg waves, Bull. Seismol. Soc. Am., 76, 495-509.

Jackson, J., D. McKenzie, K. Priestley, and B. Emmerson (2008), New views on the structure and rheology of the lithosphere, J. Geol. Soc., 165, 453-465, doi:10.1144/0016-76492007-109.
Jödicke, H., A. Jording, L. Ferrari, J. Arzate, K. Mezger, and L. Rüpke (2006), Fluid release from the subducted Cocos plate and partial melting of the crust deduced from magnetotelluric studies in southern Mexico: Implications for the generation of volcanism and subduction dynamics, J. Geophys. Res., 111, B08102, doi:10.1029/2005JB003739.

Kennett, B. L. N., and E. R. Engdahl (1991), Travel times for global earthquake location and phase association, Geophys. J. Int., 105, 429-465, doi:10.1111/j.1365-246X.1991.tb06724.x.

Lay, T., and T. C. Wallace (1995), Modern Global Seismology, Int. Geophys. Ser., vol. 58, Academic, San Diego, Calif.

Manea, V., M. Manea, V. Kostoglodov, and G. Sewell (2005), Thermomechanical model of the mantle wedge in central Mexican subduction zone and a blob tracing approach for the magma transport, Phys. Earth Planet. Inter., 149, 165-186, doi:10.1016/j.pepi.2004.08.024.

Manea, V., M. Manea, V. Kostoglodov, and G. Sewell (2006), Intraslab seismicity and thermal stress in the subducted Cocos plate beneath central Mexico, Tectonophysics, 420,389-409, doi:10.1016/j.tecto. 2006.03.029.

Pardo, M., and G. Suarez (1995), Shape of the subducted Rivera and Cocos plates in southern Mexico: Seismic and tectonic implications, J. Geophys. Res., 100, 12,357-12,373, doi:10.1029/95JB00919.

Pérez-Campos, X., Y. Kim, A. Husker, P. M. Davis, R. W. Clayton, A. Iglesias, J. F. Pacheco, S. K. Singh, V. C. Manea, and M. Gurnis (2008), Horizontal subduction and truncation of the Cocos plate beneath central Mexico, Geophys. Res. Lett., 35, L18303, doi:10.1029/ 2008GL035127.

Simkin, T., and L. Siebert (2002-2007), Global Volcanism FAQs, Global Volcanism Program Digit. Inf. Ser. GVP-5, Smithson. Inst., Washington, D. C.

Stacey, F. D. (1992), Physics of the Earth, 3rd ed., Brookfield, Brisbane, Queensl., Australia.

Stein, C. A., and S. Stein (1992), A model for the global variation in ocean depth and heat flow with lithospheric age, Nature, 359, 123-129, doi:10.1038/359123a0.

Syracuse, E. M., and G. A. Abers (2006), Global compilation of variations in slab depth beneath arc volcanoes and implications, Geochem. Geophys. Geosyst., 7, Q05017, doi:10.1029/2005GC001045

Turcotte, D. L., and G. Schubert (2002), Geodynamics, 2nd ed., Cambridge Univ. Press, New York.

Valdes, C. M., W. D. Mooney, S. K. Singh, R. P. Meyer, C. Lomnitz, J. H. Luetgert, C. E. Helsley, B. T. R. Lewis, and M. Mena (1986), Crustal structure of Oaxaca, Mexico, from seismic refraction measurements, Bull. Seismol. Soc. Am., 76, 547-563.

van der Lee, S., and G. Nolet (1997), Seismic image of the subducted trailing fragments of the Farallon plate, Nature, 386, 266-269.

P. M. Davis and A. Husker, Department of Earth and Space Sciences, University of California, 595 Circle Drive East, Los Angeles, CA 90095, USA. 